\title{
Young adult advice for kids and teens with a bleeding disorder
}

\section{Opinion}

I am twenty-one years old and I have three bleeding disorders: Hemophilia B, Von Willebrand's Disease and a platelet function defect. Until last year, I only knew about the hemophilia. I would like to give advice to my all of my younger blood brothers and sisters. I've learned these lessons from my life experiences and I hope that they will prove beneficial for you as well. I want to talk to you about the importance of self-infusion, educating your friends and finally how your bleeding disorder can help with your education.

First, let's start with self-care which is something that is a little scary and still a really big responsibility. The importance of learning how to administer your medicine is perhaps the most important thing a hemophiliac or anyone with a bleeding disorder can learn. I think that learning how to do it at a young age is best but everyone learns at their own place. I learned around the age of eleven, but I really didn't have to think about infusing on my own until I was getting ready to go on a class trip to Italy years later. I have been very fortunate and only infuse on demand or because of accidents. To make sure I knew what to do, I worked with a hematology nurse and practiced infusing for two weeks prior to the trip. Even if you think you got it down, if you haven't done it in awhile, you may need to practice. You need to be very comfortable that you know what to do in an emergency without feeling completely overwhelmed. Being able to self-administer your medication can open or close doors to possibilities you may have considered. If I didn't learn how to infuse, my parents would not have let me go on that trip to Italy. I also was able to play several sports and join different groups because of my ability to control my disorder. You aren't in this alone, make sure you have backup. I've taught several friends and my college roommates how to stick me. This creates an even greater safety net, just in case you are not able to stick yourself.

Second, talk about your disorder and spread awareness. I know several people that don't bring up their bleeding disorder because they are shy or worry that people will treat them differently. Teaching people about your bleeding disorder helps spread awareness and educates the public. Most people who have heard of hemophilia only heard of it because of one chapter in biology in high school. All of my friends are aware of my bleeding disorder because I wanted to educate them and answer any questions they might have about it. It has even gotten to the point that if they are with me and someone
Volume 2 Issue 6 - 2016

\author{
Cody A Bishop \\ Hemophilia Advocate, University of Mississippi, USA
}

Correspondence: Cody A Bishop, Student \& Hemophilia Advocate, University of Mississippi, Memphis, USA, Tel 901-3788582, Email cody.a.bishop@hotmail.com

Received: October 26, 2016 | Published: October 27, 2016

new asks about hemophilia, they can answer some of their answers as well. Having a group of friends that understand you, your needs, your limitations, and helps you overcome them is a truly incredible feeling.

Third, do all that you can to help your parents provide you with a good education? Do your best in school. Participate in extra-curricular activities and community events. College is difficult and expensive. You need to know that are many scholarships for people with bleeding disorders. Additionally, there are some paid internships for people with bleeding disorders with some of the pharmaceutical companies. Helping in your bleeding disorder community can usually satisfy community service requirements for scholarships and widen your circle of friends and mentors. If you need help finding scholarships, check out the HFA or NHF websites or ask your local chapter for help. Your bleeding disorder makes you unique, so own it and stand out. Your college expenses could be partially or totally paid and take that burden off your parents.

I hope that this advice has helped motivate you to self-administer your medication or to teach someone else how to do it. I want you to understand the importance of educating your friends and other people in your life. Also, I want you to see how your disorder can help you go to college to pursue your dreams without draining your parents. Good luck, my brothers and sisters!

\section{Acknowledgements}

None.

\section{Conflict of interest}

The author declares no conflict of interest. 